\title{
The desirability of a permanent tax amnesty
}

\author{
James Andreoni* \\ University of Wisconsin-Madison, Madison, Wisconsin 53706, USA \\ Received March 1990, revised version received November 1990
}

There are two main concerns about tax amnesty. First, if it is anticipated it may increase cheating and reduce the efficiency of the tax system. Second, amnesty may be inequitable by letting cheaters 'off the hook'. However, several federal governments currently hold a policy of long-term, or permanent, tax amnesty, in apparent defiance of these concerns. This paper examines fully anticipated tax amnesty and finds that it is possible for a permanent tax amnesty to actually increase, rather than decrease, the efficiency and equity of the tax system.

\section{Introduction}

Tax amnesties are government programs that forgive all or part of the penalties owed by tax cheaters if they voluntarily repay their delinquent taxes. Since 1981, at least 33 of America's 50 state legislatures have approved temporary tax amnesties, most lasting about three months. All of these amnesties applied to cheaters who could not have reasonably anticipated the amnesty. Nearly all of these amnesties raised significant amounts of revenue. For instance, New York raised $\$ 401$ million, while California, Illinois, Michigan, and New Jersey raised over $\$ 100$ million each. ${ }^{1}$ France, Italy, and Switzerland have also recently held tax amnesties, and an amnesty in Ireland in 1988 collected over $\$ 144$ million. In addition to raising short-term revenues, amnesties are also believed to raise long-term revenues by adding many former non-filers to the rolls. Also, amnesties are thought to ease the political transition to stiffer penalties. However, there are also concerns that amnesties may weaken incentives for tax compliance, especially if people expect that amnesties may be coming again in the future. Hence, amnesties

\footnotetext{
*I am grateful to Jonathan Feinstein, Pierre Pestieau, Joel Sobel, Louis Wilde, Shlomo Yitzhaki, and anonymous referees for helpful comments. Any errors are my own.

${ }^{1}$ See Mikesell (1986) for a survey and analysis of state amnesties. In addition, Leonard and Zeckhauser (1987) provide an excellent discussion of amnesty, highlighting its advantages and disadvantages. For a current summary of the state experiences with amnesties, see the Federation of Tax Administrators (1990).
} 
may cause a fall in tax revenues, and thereby reduce the efficiency of the tax system. $^{2}$ For this reason many plans explicitly forbid repeat amnesties in the near future. A second concern about amnesty is that it may be unfair to those who pay their taxes honestly and on time. By letting 'dishonest' people 'off the hook', amnesty may reduce the equity of the tax system.

In contrast to these state amnesties, there are several cases in which the federal government has experience with long-term, fully anticipated, forms of tax amnesty. ${ }^{3}$ For instance, between 1919 and 1952 the U.S. Bureau of Internal Revenue maintained an explicit policy of granting criminal immunity to tax evaders who voluntarily paid their delinquent taxes. An identical policy is currently observed in Canada. Since 1961 there has been a less welldefined policy of the U.S. Internal Revenue Service concerning voluntary disclosure. Before deciding to prosecute a tax cheater, the IRS will consider whether the infraction was voluntarily disclosed. Hence, evaders with skilled and knowledgeable tax practitioners can often avoid a large share of the penalties by confessing to the IRS. Although less well known, and perhaps less generous than the programs offered in the states, these policies nonetheless amount to permanent forms of tax amnesty.

The 1919-1952 policy, the current Canadian policy, and the U.S. policy of voluntary disclosure are subject to the same concerns expressed about temporary tax amnesties. In particular, since these amnesties are fully anticipated, the potential evaders can use the amnesty to their greatest advantage. Permanent tax amnesties should do more to weaken compliance than unanticipated tax amnesties, and more to skew the tax system in favor of cheaters. Nonetheless, both the Canadian and U.S. governments currently maintain forms of permanent tax amnesty.

These federal policies lead one to ask if perhaps a permanent amnesty could actually be beneficial. Specifically, could amnesty increase, rather than decrease, equity and efficiency? This paper will address this question with a theoretical model of permanent tax amnesty. Since the amnesty is permanent, the model will capture the worst fears about both anticipated and unanticipated amnesties. We assume that people are motivated to accept the amnesty because shocks to their consumption make them unwilling to bear the risk of an audit. It is found that it is possible that both efficiency and equity can he enhanced by tax amnesty. There are two reasons for this. First, amnesty tends naturally toward budget balance. In particular, the only people who will increase cheating in anticipation of the amnesty are those who are likely to file an amnesty claim. Second, the evaded tax has value as an option under amnesty. Cheaters with uncertain consumption ex ante will exercise their option for the amnesty if ex post they suffer sufficiently bad luck and

\footnotetext{
${ }^{2}$ This reason was cited by several federal officials who opposed tax amnesty. See New York Times, 5 March 1986.

${ }^{3}$ See Talley and Morrison (1984) for a detailed discussion.
} 
wish to eliminate some of their risk. In this way the amnesty acts as a partial social insurance. The amnesty allows those with low risks or good luck to separate themselves from those with high risks or bad luck. Ex ante the amnesty shifts utility from the good states to the bad states, while ex post the amnesty increases the utility of those who actually suffer the worst shocks. Hence, amnesty can increase both the equity and efficiency of taxes.

In the following sections we construct a standard model of tax evasion and then generalize the model to include an amnesty. We discuss how amnesty will affect cheating, tax revenues, welfare, and equity.

\section{Background: The no-amnesty model}

Consider a person who lives for one period. Assume that the person has an income endowment $w$ and faces a tax rate $t .^{4} \mathrm{We}$ assume that the government cannot observe $w$ directly, but relies on taxpayers to self-report their incomes. The government is assumed to enforce compliance through random audits. Let $p$ be the probability that an individual is audited. If an audit occurs, we assume that the government always learns the true $w$. Furthermore, we assume $p$ is credibly set by the government at the beginning of the period and that it is independent of reported income. ${ }^{5} \mathrm{We}$ also assume that, perhaps for legal reasons, people cannot buy insurance against possible audits.

If the taxpayer reports the truth, then consumption is $C=w(1-t)=\bar{w}$. Suppose instead that income is under-reported by an amount $x$. If this cheating goes undetected, so that the cheater wins, then consumption is $C^{W}=\bar{w}+t x$. If, on the other hand, the individual is audited, then the person is made to pay the taxes owed, $t x$, plus a fine of $\gamma$ per dollar of underreporting, $\gamma x$. When cheating is detected, so that the person loses, consumption is $C^{L}=\bar{w}-\gamma x$.

Let preferences be represented by an expected utility function $u(C)$. Assume people are risk averse: $u^{\prime}>0, u^{\prime \prime}<0$. Then the consumer choice problem with no amnesty is

$$
\max _{x} U^{N}=p u\left(C^{L}\right)+(1-p) u\left(C^{W}\right) .
$$

\footnotetext{
${ }^{4}$ These results also generalize to the case of elastic labor supply. See Andreoni (1989a).

${ }^{5}$ This assumption follows Allingham and Sandmo (1972), Yitzhaki (1974), Reinganum and Wilde (1985), Scotchmer (1987), Border and Sobel (1987), and others who assume that individuals always believe the announced policy and that the policy is always carried out, even if it does not maximize tax revenues ex post. For an example of an auditing study in which the government cannot credibly commit to $p$, see Reinganum and Wilde (1986). For audit probabilities that depend on $x$, see Greenberg (1984), Border and Sobel (1987), and Scotchmer (1987). Also, Mookherjee and Png (1989) argue that randomness in audits should be part of an optimal audit policy. This paper will maintain this more simple structure because it will allow us to include risk aversion, and to identify the direct effects of the amnesty.
} 
Under these assumptions, one dollar of cheating will have an expected value of $\mu=(1-p) t-p \gamma$. Notice that choosing to cheat is like accepting a free gamble. Therefore, given that people are risk averse, the government can eliminate cheating simply by choosing $p$ and $\gamma$ so that $\mu \leqq 0$. However, it may not be efficient for the government to do so. One reason is that audits (i.e. high $p$ ) are costly. If there are institutional or feasibility constraints on the size of $\gamma$ (for example, the penalty cannot exceed residual wealth), then, as Allingham and Sandmo, Scotchmer, and others show, cheating is part of an optimal auditing plan. This paper takes as its point of departure that cheating incentives exist. Although the audit policy need not be chosen optimally for the following results to hold, it is useful to consider that it is. If a tax and audit policy is chosen optimally without considering a permanent tax amnesty, and if adding an amnesty improves welfare further, then it necessarily follows that amnesty should be part of an efficient tax and audit system. ${ }^{6}$ The next section discusses the effects of adding an anticipated tax amnesty. After that we discuss the necessary conditions for amnesty to improve equity and efficiency.

\section{An anticipated tax amnesty}

Suppose that after people initially report income $w-x$ the government allows them to revise their reports to the truthful level, $w$. If they do so, the government will forgive a fraction $1-\alpha$ of their fine. Hence, $\alpha=1$ is full amnesty and $\alpha=0$ is no amnesty. If the taxpayer accepts the amnesty, then he will have consumption $C^{\mathrm{A}}=\bar{w}-(1-\alpha) \gamma x$.

Reflecting on the model of section 2 it becomes clear that one important generalization will be necessary to make the amnesty question both realistic and interesting. In particular, we must assume that there are uncertainties that will be resolved after the initial report is filed, but before the amnesty is allowed. $^{7}$ To see this, consider a world of perfect certainty. Before being subjected to an audit, individuals will choose $x$ optimally. Suppose that this initial choice is made with full knowledge of the state of the world that will evolve when the amnesty is offered. Given this certainty, the amnesty will not pcrmit a pcrson any opportunitics that could not have been attained without it. It follows from revealed preference that the amnesty will be completely

\footnotetext{
${ }^{6}$ The objective of this paper is simply to establish that a permanemt lax annesty could be desirable. Given that it is desirable, then many more research questions can be asked. For instance, how will the introduction of the amnesty affect the optimal penalties and audit probabilities? These questions are beyond the scope of the current paper, but are important and interesting topics for future research.

${ }^{7}$ Alternatively, we could consider a dynamic model with imperfect capital markets, i.e. borrowing constraints. As is shown in Andreoni (1989b), borrowing constraints may actually increase the beneficial effects of the amnesty. The effects discussed in this model will still exist when borrowing constraints are considered.
} 
benign: no rational person would plan to accept the amnesty. Only if the world changes unexpectedly from the time the initial report is made can the person find that he wishes to change his position in his 'investment' in cheating. This will be formally demonstrated later.

To include uncertainty, assume that consumption is subject to some random and uninsurable shock, $\varepsilon$. The shock may be uninsurable because of moral hazard, like the deductible on accident insurance, or because it cannot be publicly observed or verified. ${ }^{8}$ Therefore, it is appropriate to think of the shock as a simple shift in needs, or of its negative as the compensation necessary to restore the person to the certainty level of consumption. The shock is assumed to be a random variable with probability distribution function $f(\varepsilon),-\infty<\varepsilon<\infty$. This transforms consumption to a random variable. To indicate this, write consumption as $c^{j}=C^{j}+\varepsilon$, for $j=\mathbf{W}, \mathrm{L}, \mathrm{A}$. Note that the model without amnesty could be trivially transformed to include these consumption shocks by simply integrating over $f(\varepsilon)$.

When people initially choose $x$, we assume that they know $f(\varepsilon)$ but not the realization of $\varepsilon$. After experiencing $\varepsilon$ they are given an opportunity for a tax amnesty. If they choose not to accept the amnesty, they face the exogenous audit probability, $p$. Let

$$
\Omega(x ; \varepsilon)=u\left(c^{\mathbf{A}}\right)-p u\left(c^{\mathbf{L}}\right)-(1-p) u\left(c^{\mathbf{W}}\right)
$$

be the ex post net utility gain from accepting the amnesty. ${ }^{9}$ Then people will take an amnesty if and only if $\Omega \geqq 0$. Although $\varepsilon$ is exogenous, people have some control over $\Omega$ through their choice of $x$. In particular, their choices will affect the set of states in which the amnesty will be claimed. Define the set function

$$
S(x)=\{\varepsilon: \Omega(x ; \varepsilon) \geqq 0\}
$$

Then if $\varepsilon \in S(x)$ the person will take the amnesty. Given this, we can write the taxpayer's expected utility under amnesty as

\footnotetext{
${ }^{8}$ For instance, one can insure health care expenses, but not health per se, and one can insure the market value of a house, but not the sentimental value of a home. It should be noted here that we are not considering how amnesty may interfere with other forms of insurance, or with other forms of risk-taking. These considerations are well beyond the scope of this paper. Although these effects are discussed briefly in section 6 of this paper, these important generalizations are left to future work.

${ }^{9}$ An earlier version of this paper assumed that people could also be audited before the amnesty [Andreoni (1989a)]. All of the results obtained with that model are retained in this simpler version. Notice that it may also be more realistic to assume that there are several periods of cheating before an amnesty is announced. However, this is also unlikely to alter the basic findings of this paper, since the prior cheating will result in a 'windfall' for the tax agency under the amnesty.
} 


$$
\begin{aligned}
E U^{\mathrm{A}} & =\int_{-\infty}^{\infty}\left(p u\left(c^{\mathrm{L}}\right)+(1 \cdot p) u\left(c^{\mathrm{W}}\right)\right) f(\varepsilon) \mathrm{d} c+\int_{S(x)} \Omega(x ; \varepsilon) f(c) \mathrm{d} \varepsilon \\
& =E U^{\mathrm{N}}+\int_{S(x)} \Omega(x ; \varepsilon) f(\varepsilon) \mathrm{d} \varepsilon,
\end{aligned}
$$

where $E U^{N}$ is the expected utility in the case wherc there is no amnesty. Notice that this model will collapse exactly to the no amnesty model when $\alpha=0$, since without the amnesty $S=\varnothing$. Note also that the second term in (1) must always be non-negative, and that it will be positive if there are any states in which the amnesty will be claimed. Hence, irrespective of its effects on $\operatorname{tax}$ revenues, amnesty will always be beneficial to the taxpayer: $E U^{\mathrm{A}} \geqq$ $E U^{\mathrm{N}}$.

\subsection{The likelihood of accepting an amnesty}

Let $\theta$ be the ex ante probability of accepting an amnesty. Then

$$
\theta(x)=\int_{S(x)} f(\varepsilon) \mathrm{d} \varepsilon
$$

It is clear that whether $\theta$ rises or falls with $x$ depends on whether $S(x)$ expands or contracts. Note that for any feasible $\varepsilon$ it must be that $\Omega(0 ; \varepsilon)=0$, hence $p u\left(c^{\mathbf{L}}\right)+(1-p) u\left(c^{\mathbf{W}}\right)$ and $u\left(c^{\mathbf{A}}\right)$ can be said to cross at $x=0$. Next, note that utility from taking the amnesty, $u\left(c^{\mathrm{A}}\right)$, is decreasing in $x$ for all $\alpha<1$, but is independent of $x$ for $\alpha=1$. Furthermore, the assumption of risk aversion is sufficient to ensure that the expected utility of not taking the amnesty, $p u\left(c^{\mathbf{L}}\right)+(1-p) u\left(c^{\mathbf{W}}\right)$, will have a unique maximum in $x$, say $x^{\prime}$. If $x^{\prime}>0$, then this implies that, at $x=0, p u\left(c^{\mathrm{L}}\right)+(1-p) u\left(c^{\mathrm{w}}\right)$ will be rising. Putting the two sides of the expression together, this means that in the neighborhood of $x=0$, $p u\left(c^{\mathrm{L}}\right)+(1-p) u\left(c^{\mathbf{W}}\right)$ and $u\left(c^{\mathbf{A}}\right)$ are growing farther apart, hence $\Omega$ must be falling. But since $\Omega(0 ; \varepsilon)=0$, then for $x$ close to zero, $\Omega<0$.

To find a place where $\Omega>0$ we must look for a place where $p u\left(c^{\mathbf{L}}\right)+$ $(1-p) u\left(c^{\mathbf{W}}\right)$ and $u\left(c^{\mathrm{A}}\right)$ cross again. If the crossing is to take place, it is clear from the above that it must be at an $x^{*}$ such that $x^{*}>x^{\prime}$, i.e. $p u\left(c^{\mathrm{L}}\right)+$ $(1-p) u\left(c^{\mathrm{W}}\right)$ cuts $u\left(c^{\mathrm{A}}\right)$ from above. This is shown in fig. 1 . Note that in fig. 1 the two lines cross only one. While one cannot rule out that they will cross again, it appears most natural that they will not. For instance, the two lines will necessarily cross only once if there is full amnesty $(\alpha=1)$, since in this case $u\left(c^{\mathbf{A}}\right)$ in fig. 1 is a simple horizontal line. Therefore, we make the following assumption:

Single crossing condition $1(S C C l)$. For all feasible $\varepsilon$ there exists at most 


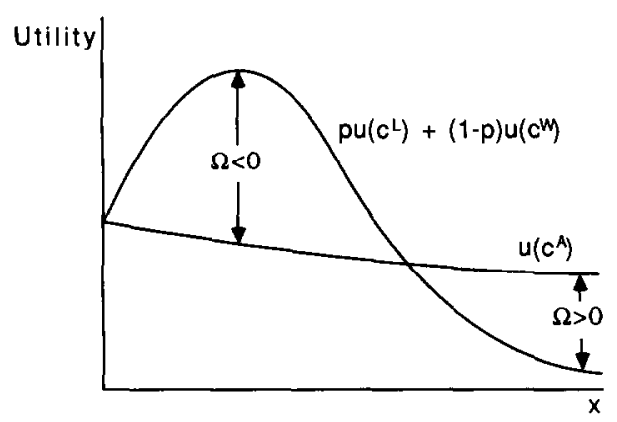

Fig. 1

one feasible $x^{*}>0$ such that $\Omega\left(x^{*} ; \varepsilon\right)=0$. Furthermore, $\Omega(x ; \varepsilon)<0$ for $0<x<x^{*}$, and $\Omega(x ; \varepsilon) \geqq 0$ for $x^{*} \leqq x$.

The implication of this condition is that the larger the $x$ the more likely it is that $x>x^{*}(\varepsilon)$ and hence the more likely it is that the amnesty will be desirable. Therefore, $\partial \theta(x) / \partial x>0$.

We can also ask how $\theta$ is affected by changes in the level of amnesty, $\alpha$. Obviously, if $\alpha$ is too small it may generate no claims. Hence, for a given $(x, \varepsilon)$ define an $\alpha^{*} \geqq 0$ such that $\Omega\left(x ; \varepsilon, \alpha^{*}\right)=0$. Then

$$
\frac{\partial \Omega\left(x ; \varepsilon, \alpha^{*}\right)}{\partial \alpha}=u^{\prime}\left(c^{\mathrm{A}}\right) \gamma x>0
$$

Again, this implies at most a single crossing:

Single crossing condition 2 (SCC2). For all feasible $(x, \varepsilon)$ there exists at most one $\alpha^{*}, 0 \leqq \alpha^{*} \leqq 1$, such that $\Omega\left(x ; \varepsilon, \alpha^{*}\right)=0$. Furthermore, $\Omega\left(x ; \varepsilon, \alpha^{*}\right) \leqq 0$ for $0 \leqq \alpha \leqq \alpha^{*}$ and $\Omega\left(x ; \varepsilon, \alpha^{*}\right) \geqq 0$ for $\alpha^{*} \leqq \alpha \leqq 1$.

This implies that increasing $\alpha$ will not induce someone to contemplate an amnesty claim unless $\alpha$ is sufficiently high. After that point, however, increases in $\alpha$ will increase the chance that the amnesty will be accepted: ${ }^{10}$ $\partial \theta(x ; \alpha) / \partial \alpha \geqq 0$.

Finally, we can ask whether, for any given $(x, \alpha)$, acceptance of the amnesty will be associated with high or low values of $\varepsilon$. Again, consider some $\varepsilon^{*}$ such that $\Omega\left(x ; \varepsilon^{*}\right)=0$. Then

\footnotetext{
${ }^{10}$ Note that $\alpha^{*}$ need not exist. It is possible that amnesty will never be accepted, even for $\alpha=1$. As indicated earlier, a world of perfect certainty is such a case.
} 


$$
\frac{\partial \Omega\left(x ; \varepsilon^{*}\right)}{\partial \varepsilon}=u^{\prime}\left(c^{\mathbf{A}}\right)-p u^{\prime}\left(c^{L}\right)-(1-p) u^{\prime}\left(c^{\mathbf{w}}\right)
$$

To evaluate this term we appeal to a well-known result of Diamond and Stiglitz (1974). Note that at $\Omega(x ; \varepsilon)=0$ the consumption in the sure state (amnesty) must equal the expected value of consumption in the unsure state minus the risk premium. ${ }^{11}$ Letting $\pi$ be the risk premium, then at $\Omega(x ; \varepsilon)=0$ it must be that $c^{\mathbf{A}}=\vec{w}+\mu x+\varepsilon-\pi$. Diamond and Stiglitz show that if $u(\cdot)$ exhibits decreasing absolute risk aversion, then $\mathrm{d} \pi / \mathrm{d} \bar{w}<0$. It is easily verified that in this case this condition implies

$$
\frac{\mathrm{d} \pi}{\mathrm{d} \bar{w}}=\frac{u^{\prime}\left(c^{\mathrm{A}}\right)-p u_{-}^{\prime}\left(c^{\mathrm{L}}\right)-(1-p) u^{\prime}\left(c^{\mathrm{W}}\right)}{u^{\prime}\left(c^{\mathrm{A}}\right)}<0 .
$$

It follows that the numerator in the above expression must be negative. This implies that (2) is also negative. Therefore, at any crossing of $p u\left(c^{\mathrm{L}}\right)+$ $(1-p) u\left(c^{\mathbf{w}}\right)$ and $u\left(c^{\mathbf{A}}\right)$ it must be that $\partial \Omega / \partial \varepsilon<0$. By continuity, this in turn implies that there can be at most one crossing, hence we have

Single crossing condition 3 (SCC3). For any feasible $x$ there exists at most one $\varepsilon^{*}, f\left(\varepsilon^{*}\right)>0$, such that $\Omega\left(x ; \varepsilon^{*}\right)=0$. Furthermore, $\Omega(x ; \varepsilon) \geqq 0$ for $\varepsilon \leqq \varepsilon^{*}$ and $\Omega(x ; \varepsilon)<0$ for $\varepsilon>\varepsilon^{*}$.

This condition implies that $\varepsilon \in S(x)$ if and only if $\varepsilon \leqq \varepsilon^{*}$. This means that for any $x$ we can write

$$
\theta(x)=\int_{-\infty}^{\varepsilon^{*}(x)} f(\varepsilon) \mathrm{d} \varepsilon
$$

Furthermore, since SCC1 implies that $\partial \theta(x) / \partial x \geqq 0$, then $\partial \varepsilon^{*}(x) / \partial x \geqq 0$.

SCC3 also gives us an important insight about how acceptance of the amnesty will be distributed ex post. Since the amnesty will be taken only if the realization of $\varepsilon$ is below $\varepsilon^{*}(x)$, this means that the amnesty will be

\footnotetext{
${ }^{11}$ Note that $\varepsilon$ is now no longer taken as a random variable, but is the realization of the random variable. The only risk is the audit risk, $p$.
} 
accepted by people who have 'bad luck'. This result can be seen intuitively. When, ex post, people have bad luck, it is equivalent to a loss of income. If their preferences exhibit decreasing absolute risk aversion, then this loss of income will cause risk aversion to rise. If the loss is bad enough, then they would be better off by eliminating the risk and accepting a sure loss of paying their delinquent taxes. The intuition for this result is similar to that in Varian (1980) - the amnesty has the same effect as a progressive tax, where the tax can be made contingent on $\varepsilon$. Hence, amnesty provides partial social insurance. $^{12}$

\subsection{The effect of amnesty on cheating}

We can now formally state the effect of introducing the amnesty. This will be shown by introducing an amnesty marginally greater than $\alpha^{*}$, as defined in $\mathrm{SCC} 2,{ }^{13}$ and then increasing $\alpha$ along the path from $\alpha^{*}$ to 1 . Note that SCC3 implies that we can write expected utility as

$$
E U^{\mathrm{A}}=E U^{\mathrm{N}}+\int_{-\infty}^{\varepsilon^{*}(x)} \Omega(x ; \varepsilon) f(\varepsilon) \mathrm{d} \varepsilon
$$

Differentiating this with respect to $x$ yields the first-order condition:

$$
\frac{\partial E U^{\mathrm{A}}}{\partial x}=\frac{\partial E U^{\mathrm{N}}}{\partial x}+\Omega^{*} \frac{\partial \varepsilon^{*}}{\partial x} f\left(\varepsilon^{*}\right)+\int_{-\infty}^{z^{*}} \frac{\partial \Omega(x ; \varepsilon)}{\partial x} f(\varepsilon) \mathrm{d} \varepsilon=0 .
$$

Totally differentiating this and solving we find

$$
\frac{\mathrm{d} x}{\mathrm{~d} \alpha}=-\frac{1}{\Delta}\left[\frac{\partial \Omega^{*}}{\partial \alpha} \frac{\partial \varepsilon^{*}}{\partial x} f\left(\varepsilon^{*}\right)+\frac{\partial \Omega^{*}}{\partial x} \frac{\partial \varepsilon^{*}}{\partial \alpha} f\left(\varepsilon^{*}\right)+\int_{-\infty}^{\varepsilon^{*}} \frac{\partial^{2} \Omega}{\partial x \partial \alpha} f(\varepsilon) \mathrm{d} \varepsilon\right],
$$

where $\Delta<0$ is the second derivative on (3). The sign of this can be determined by the single crossing conditions. By SCC1 we know that $\partial \varepsilon^{*} /$ $\partial x>0$ and that $\partial \Omega^{*} / \partial x>0$. By SCC2 we know that $\partial \varepsilon^{*} / \partial \alpha>0$ and that $\partial \Omega^{*} /$

\footnotetext{
${ }^{12}$ It should also be noted that although amnesty provides insurance, it by no means completes the market for insurance. Other superior mechanisms for providing insurance may be possible. To the extent that other forms of insurance reduce risk, they will diminish both the increase in cheating and the amnesty claims. If other mechanisms completely insure income risk (but not audit risk) then they will make amnesty moot. This is because, in this model, uncertainty in consumption is neccssary for amnesty to be claimed.

${ }^{13}$ To make the question interesting, we will assume $0 \leqq \alpha^{*}<1$.
} 
$\partial \alpha>0$. It is also easily verified that $\partial^{2} \Omega / \partial x \partial \alpha>0$. It follows that $\mathrm{d} x / \mathrm{d} \alpha \geqq 0$. Hence, amnesties will increase cheating. ${ }^{14}$

We can characterize the effect of the amnesty more precisely by noting that SCC3 allows us to write $\partial \theta / \partial \alpha=f\left(\varepsilon^{*}\right) \partial \varepsilon^{*} / \partial \alpha$. Furthermore, from the definition of $\Omega^{*}\left(x ; \varepsilon^{*}\right) \equiv 0$ we can write

$$
\frac{\mathrm{d} \varepsilon^{*}}{\mathrm{~d} \alpha}=-\frac{\partial \Omega^{*} / \partial \alpha}{\partial \Omega^{*} / \partial \varepsilon}, \quad \frac{\mathrm{d} \varepsilon^{*}}{\mathrm{~d} x}=-\frac{\partial \Omega^{*} / \partial x}{\partial \Omega^{*} / \partial \varepsilon}
$$

Substituting these into (4) and rearranging we find

$$
\begin{aligned}
\frac{\mathrm{d} x}{\mathrm{~d} \alpha} & =-\frac{1}{\Delta}\left[2 \frac{\partial \Omega^{*}}{\partial x} \frac{\partial \theta}{\partial \alpha}+\int_{-\infty}^{\varepsilon^{*}(x)} \frac{\partial^{2} \Omega^{*}}{\partial x \partial \alpha} f(\varepsilon) \mathrm{d} \varepsilon\right] \\
& =A \frac{\partial \theta}{\partial \alpha}+B
\end{aligned}
$$

where $A, B \geqq 0$, and $A=B=0$ if $S=\varnothing$. This expression gives us a direct relationship between $x$ and $\theta$. We see that although an increase in amnesty will increase $x$, it will also increase $\theta$. Moreover, the increase in each will be directly proportional. Hence, amnesty may increase cheating, but it will only do so to the extent that it also encourages participation in the amnesty program. Stated differently, dramatic rises in cheating are likely to be accompanied by vast numbers of amnesty claims, and vast numbers of claims are more likely if there is a large increase in cheating.

\section{Efficiency and equity}

First look at the hypothesis that an anticipated amnesty will reduce tax revenues. Consider a marginal increase in $\alpha$. A marginal increase in $\alpha$ is associated with marginal increases in both $\theta$ and $x$. These two affect revenues in opposite directions. However, as we saw in the previous section, the effects are proportional. Cheating will only rise rapidly if acceptance of the amnesty also increases rapidly. More importantly, however, the marginal change in $\theta$ is also associated with an increased probability that both the marginal and

\footnotetext{
${ }^{14} \mathrm{We}$ can see that amnesty would be benign under perfect certainty. If the future state is known at the time that $x$ is chosen, then the person must also know whether $\theta=0$ or $\theta=1$. But, if $\theta=1$, then the person will be just as well off with $x=0$ at the start (and strictly better off if we add transactions costs of amnesty). Hence, if the future is certain and $x>0$, then it must be that $\theta=0$. Therefore, in this model, the amnesty will only affect those who face risk to thcir consumption.
} 
infra-marginal cheating will be recaptured by the government. It is easily demonstrated [Andreoni (1989a)] that net tax revenue will rise if

$$
\frac{\mathrm{d} x / \mathrm{d} \alpha}{\partial \theta / \partial \alpha}<\frac{\mu+(1-\alpha) \gamma}{\mu} x
$$

where this expression is evaluated at the individual's optimum. This expression indicates that the larger the initial cheating, the greater the chance that the amnesty will increase revenue. Hence, the effect of amnesty on revenues may depend more critically on the amount of cheating that exists without the amnesty than on the increase in cheating that the amnesty may cause. If existing cheating is sizable, then the revenue gains from anticipated tax amnesties become more certain, and the induced cheating becomes less relevant. If $\operatorname{tax}$ revenues rise, then amnesty will not necessarily dilute economic efficiency. In fact, the amnesty could be Pareto improving. However, even if tax revenues decline, the amnesty may still be efficient because of its value as an option. Individuals may be willing to accept certain tax increases in order to gain the insurance benefits of the amnesty. Hence, the efficiency of any enforcement policy may be improved by amnesty.

We can address the question of equity by asking how the benefits of amnesty will be distributed across taxpayers. Notice first that, ex ante, those with a higher risk of bad luck are more likely to claim the amnesty than those with little or no risk. Hence, the benefits of the amnesty will be felt most by those with the highest risk and, all else equal, the lowest expected utility. From the ex ante perspective, therefore, amnesty may increase the equity of the tax system. Notice, however, that the same is true ex post. Those who actually realize bad luck will be the ones who make the amnesty claims. Hence, those who are actually worst off ex post will be the ones who are, ex post, made better off by the amnesty. Hence, from both ex ante and ex post perspectives, the amnesty may increase the equity of the tax system.

This discussion, of course, ignores the question of whether amnesty treats 'honest' taxpayers equitably relative to 'dishonest' taxpayers. ${ }^{15}$ According to the analysis in this paper, people with identical market characteristics are assumed to differ in their cheating because of risk aversion: dishonesty and low risk aversion are synonymous. If, on the other hand, one believes that honest reporting is due to ethics rather than risk aversion, then an argument may be made that amnesty favors those with lower ethical standards. This is especially true if amnesty requires raising taxes, which means that the honest

\footnotetext{
${ }^{15}$ For a detailed treatment of this, see Sandmo (1981). Identical arguments can be made with respect to differences in the opportunity to cheat, e.g. those who are sclf-cmployed versus those who face a payroll deduction.
} 
people may have to pay part of the insurance benefits granted to dishonest people. However, if amnesty increases tax revenues, then only the dishonest people will see their tax payments rise. In this case, the honest people may benefit the most since they will share in the tax cut that the amnesty makes possible. Therefore, even if only dishonest people get the direct benefit of the amnesty, it may still treat the honest taxpayers equitably. ${ }^{16}$

\section{An example}

This section presents a simple algebraic example of amnesty. Although the example is simple, it captures all of the important elements of the model just presented.

Assume that all individuals have identical utility functions of the form

$$
U_{i}= \begin{cases}c, & \text { if } 0<c, \\ (1+b) c, & \text { if } c \leqq 0\end{cases}
$$

where $b>0$. An individual with these preferences is locally risk averse around the point $c=0$, and absolute risk aversion is decreasing over the relevant range. Assume that for each individual $i, \varepsilon_{i}$ takes on only two possible values, one good and one bad:

$$
\varepsilon_{i}=\left\{\begin{aligned}
0, & \text { with probability } 1-\pi_{i}, \\
-\bar{w}, & \text { with probability } \pi_{i} .
\end{aligned}\right.
$$

Therefore, if the person tells the truth and then suffers bad luck, consumption will be zero. Also, assume $t+\gamma<1$ and $\mu>0$.

If $\pi_{i}=\mathbf{0}$ (that is, there is no chance of bad luck) then these assumptions ensure that the person will choose $x_{i}=w$. This is because the person will be risk neutral across all possible consumption levels. However, if $\pi_{i}>0$, then the person will be risk averse. If $\pi_{i}$ is sufficiently high, therefore, the person will find it optimal to switch from $x_{i}=w$ to $x_{i}=0$. This can be seen by writing the expected utility problem for the case of no amnesty:

$$
E U_{i}^{\mathrm{N}}=\left(1-\pi_{i}\right)\left\{(1-p)\left(\bar{w}+t x_{i}\right)+p\left(\bar{w}-\gamma x_{i}\right)\right\}+\pi_{i}\left\{(1-p) t x_{i}-p(1+b) \gamma x_{i}\right\}
$$

\footnotetext{
${ }^{16}$ If cheaters are given lower welfare weight in a social welfare function than honest taxpayers, then amnesty may reduce welfare (even if revenues rise and each individual's utility rises) simply by converting sufficient numbers of honest people to cheaters. I thank an anonymous referee for this point.
} 


$$
=\left(1-\pi_{i}\right) \bar{w}+\left\{\mu-\pi_{i} p b \gamma\right\} x_{i}
$$

Hence, cheating will be either zero or $w$ depending on whether the bracketed term in (5.2) is negative or positive. Let $\pi^{*}=\mu /(p b \gamma)$. Then cheating will be positive if and only if $\pi_{i}<\pi^{*}$. Therefore, at the optimum

$$
E U_{i}^{\mathbf{N}}= \begin{cases}\left(1-\pi_{i}\right) \bar{w}+\left\{\mu-\pi_{i} p b \gamma\right\} w, & \text { if } \pi_{i}<\pi^{*}, \\ \left(1-\pi_{i}\right) \bar{w}, & \text { if } \pi_{i} \geqq \pi^{*}\end{cases}
$$

As indicated earlier, the amount of cheating depends critically on the amount of other risk a person faces.

Next consider the effects of amnesty. One can notice immediately that an amnesty will never be claimed if the person experiences good luck, since in that state the person is risk neutral. If the person experiences bad luck and accepts amnesty, then consumption will be $c^{\mathrm{A}}=0$. Drawing from the last term in (5.1), an amnesty will be desirable if and only if $\Omega=-(1-p) t w+$ $p(1+b) \gamma w=-(\mu-p b \gamma) w>0$. We will assume that the parameters are chosen so that this is true. ${ }^{17}$

We can now write the expected utility of choosing $x=w$, and then choosing the amnesty if the bad state occurs, as

$$
\begin{aligned}
E U_{i}^{\mathbf{A}} & =\left(1-\pi_{i}\right)\{(1-p)(\bar{w}+t w)+p(\bar{w}-\gamma w)\} \\
& =\left(1-\pi_{i}\right)(\bar{w}+\mu w) .
\end{aligned}
$$

Comparing this with (6) we see that $E U^{A}$ is greater than the utility of cheating without the amnesty, and is also greater than the utility of truthtelling. Hence, when the amnesty is allowed, cheating will increase among those with $\pi_{i} \geqq \pi^{*}$, that is, everyone will cheat. However, all those with bad luck will accept the amnesty.

We can also use this example to show that tax revenues will rise if initial cheating is sufficiently high. Without the amnesty, cheaters have an expected tax bill of $t w-\mu w$, while truth-tellers simply pay $t w$. However, with amnesty each individual will have an expected tax bill of $t w-\left(1-\pi_{i}\right) \mu w$. Hence, under amnesty the expected tax bill of initial cheaters rises by $\pi_{i} \mu w$, while the expected tax bill of initial truth-tellers falls by $\left(1-\pi_{i}\right) \mu w$. Assume, for the sake of illustration, that $\pi_{i}$ is distributed uniformly on the unit interval. Then the expected change in tax revenue is

\footnotetext{
${ }^{17}$ Rearranging the inequality $\Omega>0$ implies that $\pi^{*}<1$. Hence, this condition is consistent with earlier assumptions of the model.
} 


$$
\begin{aligned}
\Delta R & =\int_{0}^{\pi^{*}} \pi \mu w \mathrm{~d} \pi-\int_{\pi^{*}}^{1}(1-\pi) \mu w \mathrm{~d} \pi \\
& =\left(\pi^{*}-1 / 2\right) \mu w .
\end{aligned}
$$

Hence, revenues will rise if and only if $\pi^{*}>1 / 2$, that is, if over half of the population is initially cheating. Comparing (6) with (7) we see that a cheater's utility rises by $\pi_{i}(p b \gamma-\mu) w$, while a truth-teller's utility goes up by $\left(1-\pi_{i}\right) \mu w$. Again, assuming a uniform distribution of $\pi$, and without considering the effects of taxes, the total change in welfare is

$$
\begin{aligned}
\Delta W & =\int_{0}^{\pi^{*}} \pi(p b \gamma-\mu) w \mathrm{~d} \pi+\int_{\pi^{*}}^{1}(1-\pi) \mu w \mathrm{~d} \pi \\
& =(1 / 2) \pi^{* 2} p b \gamma w-\left(\pi^{*}-1 / 2\right) \mu w>0
\end{aligned}
$$

To complete the example, we must consider the net effect of a balanced budget tax amnesty. Obviously, if tax revenues rise, then everyone's taxes can be cut and the amnesty can be Pareto improving. Suppose instead that tax revenues fall, that is, $\pi^{*}<1 / 2$. Also, assume that the budget can be balanced by raising simple lump-sum levies of $\tau=-\Delta R$ for all $i$, and that $\tau$ is sufficiently small so that $c^{\mathrm{L}}>0$ in the good state, and that $c^{\mathbf{w}}>0$ in the bad state. Then it can easily be shown that this levy will not change the margins of the above problem, since it will not effect $\pi^{*}$ or $\Omega$, and that the effect will be to reduce utility of each individual by $\tau\left(1+\pi_{i} b\right)$. Integrating this over $\pi$, we find that the aggregate utility loss from the budget-balancing levy is $\tau(1+b / 2)$. Subtracting this from $\Delta W$ above, substituting $\tau=-\Delta R$, and rearranging we see

$$
\begin{aligned}
\Delta W^{\mathbf{B}} & =(1 / 2) \pi^{2} p b \gamma w+\left(\pi^{*}-1 / 2\right) b \mu w / 2 \\
& =(1 / 2) \pi^{* 2} p b \gamma w+b \Delta R / 2
\end{aligned}
$$

Hence, even if revenue declines there is still room for a welfare gain. Rearranging (8) and simplifying, it is easy to show that welfare will rise as long as $\pi^{*} \geqq b /(2+2 b)$, where $b /(2+2 b)<1 / 2$ for finite $b$. Fig. 2 illustrates the regions over which amnesty will increase revenues and welfare. As $b$ increases, individuals become more risk averse and pre-amnesty cheating declines. As pre-amnesty cheating declines, the direct benefit of amnesty diminishes, and it becomes less likely that amnesty will increase tax revenues. However, there exists a region where the amnesty can increase welfare even though revenues fall. 


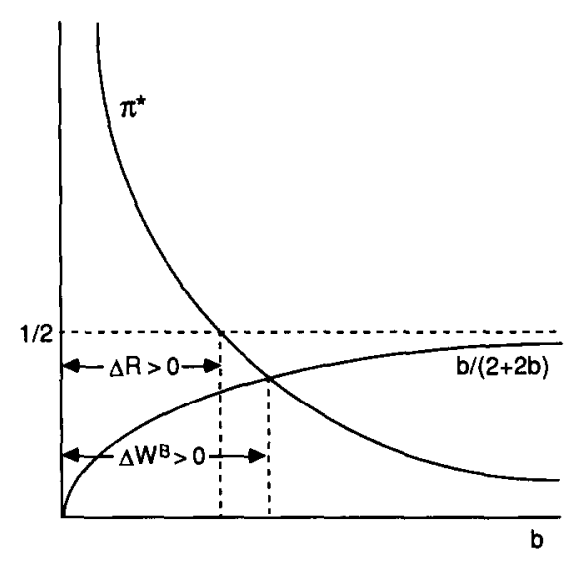

Fig. 2

We can also see from (8) that amnesty is beneficial as insurance. In particular, if people are everywhere risk neutral $(b=0)$, then the policy would have no effect. And finally, amnesty does not diminish the equity of the tax system. Ex ante it increases utility the most for those with the greatest probability of bad luck, while ex post amnesty only increases utility for those who actually suffer bad luck. Moreover, amnesty shifts taxes from those who were initially honest to those who began as cheaters.

\section{Conclusion}

This paper indicates that although cheating will rise as a result of the amnesty, it does not directly follow that tax revenues will also fall. In particular, cheating will rise only to the extent that people expect to participate in the amnesty. If they do participate, the government will recapture not only the new cheating, but the pre-existing cheating as well. Hence, the most crucial variable for determining whether revenue will rise or fall as a result of the amnesty may be the level of pre-existing cheating, and not the change caused by the amnesty. If initial cheating is large, the amnesty may increase tax revenue even if the amnesty generates large increases in cheating - and perhaps because it generates large increases in cheating. It is possible, therefore, that the amnesty could be Pareto improving.

However, even if tax revenues decline because of the amnesty, the amnesty provides certain insurance benefits that may justify it on efficiency grounds. In particular, people will only be affected by the amnesty if they face risky consumption, and will only exercise their amnesty option if they suffer a sufficiently bad shock to their consumption. This implies that the amnesty is 
partially completing the market for social insurance. Hence, even if taxes need to rise as a result of the amnesty, the net effect may still be positive.

Since amnesty has insurance benefits, we can ask if there is a potential problem of moral hazard. Suppose, for instance, that the above model were generalized to allow people at least some control over the amount of risk they face. Then the amnesty may lead them to more risky portfolios. If this is the case, the amnesty will provide some partial portfolio insurance. Certainly this will make the individual better off, and if risk-taking is good for the economy, then the amnesty may have other benefits as well. A similar argument could be made with respect to the choice of safe versus risky occupations: amnesty could lead to more entrepreneurship. ${ }^{18}$ However, if there are private insurers who provide benefits that would compete with the amnesty, then it may be possible that the insurance benefits provided by the amnesty may disrupt the incentives in the private markets [Kahn and Mookherjee (1988)]. This could dampen the efficiency gains discussed above.

There are obviously many other aspects of cheating that, unfortunately, this model cannot address. For instance, people may face borrowing constraints and may use cheating as a way to transfer resources to the present. In this case, cheating and amnesty may be used to remedy the lack of a perfect capital market [see Andreoni (1989b)]. Again, amnesty may increase cheating, but it may also have other beneficial effects that will improve efficiency. Given that amnesty may be a desirable part of a tax compliance policy, future work may consider optimal tax and audit policies that explicitly include a permanent tax amnesty.

${ }^{18}$ I would like to thank Pierre Pestieau for suggesting this extension.

\section{References}

Allingham, Michael G. and Agnar Sandmo, 1972, Income tax evasion: A theoretical analysis, Journal of Public Economics 1, 323-338.

Andreoni, James, 1989a, The desirability of a permanent tax amnesty, Social Systems Research Institute working paper 8901 (University of Wisconsin, Madison).

Andreoni, James, 1989b, IRS as loan shark: The optimality of tax evasion in the presence of borrowing constraints, Social Systems Research Institute working paper 8907 (University of Wisconsin, Madison).

Border, Kim and Joel Sobel, 1987, Samurai accountant: A theory of audit and plunder, Review of Economic Studies 54, 525-540.

Diamond, Peter A. and Joseph E. Stiglitz, 1974, Increases in risk and risk aversion, Journal of Economic Theory 8, 337-360.

Federation of Tax Administrators, 1990, State tax amnesty programs, Research report no. 133 (Washington, DC).

Greenberg, Joseph, 1984, Avoiding tax avoidance: A (repcated) game-theoretic approach, Journal of Economic Theory 32, 1-13.

Kahn, Charles and Dilip Mookherjee, 1988, Decentralized coalition formation with moral hazard, Mimeo.

Leonard, Herman B. and Richard Zeckhauser, 1987, Amnesty, enforcement and tax policy, in: L. Summers, ed., Tax policy and the economy, Vol. 1 (NBER and MIT Press, Cambridge). 
Mikesell, John L., 1986, Amnesties for state tax evaders: The nature of and response to recent programs, National Tax Journal 39, 507-527.

Mookherjee, Dilip and Ivan Png, 1989, Optimal auditing, insurance, and redistribution, Quarterly Journal of Economics 54, 399-416.

Reinganum, Jennifer F. and Louis L. Wilde, 1985, Income tax compliance in a principal-agent framework, Journal of Public Economics 26, 1-18.

Reinganum, Jennifer $F$. and Louis $L$. Wilde, 1986, Equilibrium verification and reporting policies in a model of tax compliance, International Economic Review 27, 739-760.

Sandmo, Agnar. 1981, Income tax evasion, labour supply and the equity-efficiency tradeoff, Journal of Public Economics 16, 265-288.

Scotchmer, Suzanne, 1987, Audit classes and tax enforcement policy, American Economic Review, Papers and Proceedings 77, 229-233.

Talley, Louis A. and Wayne M. Morrison, 1984, Tax amnesty: State and European experience, Publication 84-603E, Congressional Research Service (The Library of Congress, Washington, DC).

Varian, Hal R., 1980, Redistributive taxation as social insurance, Journal of Public Economics $14,49-68$.

Yitzhaki, Shlomo, 1974, A note on income tax evasion: A theoretical analysis, Journal of Public Economics 3, 201-202. 